\title{
DYNAMIC MODELS IN SOCIOLINGUISTICS AND SOCIO-COMMUNICATIVE ATTITUDES OF THE RUSSIAN LANGUAGE PERSONALITY IN THE POST-SOVIET PERIOD
}

\author{
Irina V. Shaposhnikova \\ Institute of Philology of Siberian Branch of Russian Academy of Sciences, Novosibirsk, Russia; \\ Novosibirsk State University, Novosibirsk, Russia
}

\begin{abstract}
The article focuses on the range of scientific issues which have been studied by sociolinguists who apply dynamic models mainly to the material of the English language. Priority is given to network models and their predecessors - the study of relationships within semantic fields. The author's observations of the circulation of the meanings as they are reflected in the Russian associative-verbal network (hereafter AVN) provide supporting evidence for the links between the dimensions of socio-communicative networks (strength, density, direction of contacts) and the emergence of favorable conditions for socially significant language changes. Sociolinguists discovered this type of correlation earlier using other methods on English materials. The instability of the social environment of the post-Soviet world manifests itself (within three generations) in the dynamics of sociocommunicative attitudes concerning the ways people manipulate the bodies of language units. Thus attested shifts in motivational orientations of the Russian language personality can be studied further on as potential activators of socially conditioned language changes. The AVN materials allow scientists to consider the psychological dimensions in their interpretations of sociolinguistically significant dynamics. The use of AVN models in the light of actual (within 3-4 generations) diachrony opens up the prospect of developing associative variantology as a new branch of experimental psychosociolinguistics; the study of the circulation of word meanings in the semantic field of culture provides valuable empirical data for ethnopolitical sociolinguistics.

Key words: network models, associative verbal network, circulation of word meanings, actual diachrony, experimental psycho-sociolinguistics, ethno-political sociolinguistics.

Citation. Shaposhnikova I.V. Dynamic Models in Sociolinguistics and Socio-Communicative Attitudes of the Russian Language Personality in the Post-Soviet Period. Vestnik Volgogradskogo gosudarstvennogo universiteta. Seriya 2. Yazykoznanie [Science Journal of Volgograd State University. Linguistics], 2019, vol. 18, no. 3, pp. 24-38. (in Russian). DOI: https://doi.org/10.15688/jvolsu2.2019.3.2
\end{abstract}

\section{ДИНАМИЧЕСКИЕ МОДЕЛИ В СОЦИОЛИНГВИСТИКЕ И СОЦИОКОММУНИКАТИВНЫЕ УСТАНОВКИ РУССКОЙ ЯЗЫКОВОЙ ЛИЧНОСТИ В ПОСТСОВЕТСКИЙ ПЕРИОД}

\section{Ирина Владимировна Шапошникова}

Институт филологии Сибирского отделения РАН, г. Новосибирск, Россия; Новосибирский государственный университет, г. Новосибирск, Россия

\footnotetext{
Аннотация. В статье представлен обзор научных проблем, для решения которых в социолингвистике используются динамические модели, созданные преимущественно на материале английского языка. Особое внимание уделено сетевым моделям и их становлению в процессе изучения смысловых связей языковых единиц в рамках семантических полей. Проведенные наблюдения за движением значений единиц ассоциативно-вербальной сети носителей русского языка подтвердили выводы о наличии зависимости между параметрами социокоммуникативных сетей (силы, плотности, направленности контактов) и возникновением
} 
И.В. Шапошникова. Динамические модели в социолингвистике и социокоммуникативные установки

условий для социально обусловленных языковых изменений, полученные ранее на английском материале с применением других методов. Неустойчивость социальной среды постсоветского пространства проявляет себя (в пределах трех поколений) в динамике социокоммуникативных установок применительно к оперированию телами языковых знаков. Смена мотивационно-установочных ориентиров русской языковой личности способствует активации социально обусловленных языковых изменений. Принципы построения ассоциативно-вербальной сети позволяют учесть психологический фактор в интерпретации социолингвистически значимой динамики. Использование ассоциативно-вербальных моделей в аспекте актуальной диахронии открывает перспективу развития ассоциативной вариантологии как раздела экспериментальной психосоциолингвистики, а изучение движения значений в смысловом поле культуры дает ценный эмпирический материал для этнополитической социолингвистики.

Ключевые слова: сетевая модель, ассоциативно-вербальная сеть, движение значений, актуальная диахрония, экспериментальная психосоциолингвистика, этнополитическая социолингвистика.

Цитирование. Шапошникова И. В. Динамические модели в социолингвистике и социокоммуникативные установки русской языковой личности в постсоветский период // Вестник Волгоградского государственного университета. Серия 2, Языкознание. - 2019. - Т. 18, № 3. - C. 24-38. - DOI: https://doi.org/10.15688/ jvolsu2.2019.3.2

\section{Введение}

Научные модели, позволяющие описать и объяснить изменчивость объекта, называют динамическими. Для социолингвистики это модели, дающие ключ к пониманию языковых процессов в части их социальной обусловленности. Эти модели, как отмечает В.А. Тишков, оказались особенно востребованными в антропологических исследованиях постсоветского времени, когда возникла острая потребность в разработке подходов для понимания новой реальности, показавшей симптомы разрывов с традицией и даже ее радикальной смены. Старые статические подходы к изучению «традиционных обществ» оказались во многом несостоятельными [Тишков, 2016, c. 101]. Быстрое исчезновение советского государства с конфликтами и противоречиями на фоне разнообразных спонтанных практик политической мобилизации этничности привело к необходимости осмыслить и объяснить суть происшедших перемен и полученного народами бывшего СССР перестроечного опыта. Вопросы динамики этносоциокультурных процессов начали разрабатываться в рамках новых дисциплин: этносоциологии, этнополитологии и др. [Губогло, 2016; Тишков, 2016; Феномен междисциплинарности..., 2016]. Одной из таких междисциплинарных отраслей стала этнополитическая социолингвистика, которая изучает функционирование и взаимодействие языков в меняющемся этносоциальном контексте [Губогло, 2016, с. 73-77]. Задачи этого направления М.Н. Губогло связывает с выявлением языковых потребностей населения и оценкой последствий «этноязыкового волюнтаризма» эпохи перестройки. «Деформацию» языковой политики в разных регионах бывшего СССР, политизацию языка, стремление решить вопросы борьбы за власть за счет игнорирования реалий языковой ситуации, в особенности роли русского языка как социального капитала и национального достояния народов РФ, автор трактует как последствия этнизации политики [Губогло, 2016, с. 73-77].

Нельзя не согласиться с М.Н. Губогло, показавшим недооценку в прошлом советской социолингвистикой этнополитических аспектов языковой жизни народов СССР и связавшим такое положение дел с характерным для прошлого акцентом на исследовании языка «вне человека», а не «на речевом поведении человека» [Губогло, 2016, с. 76]. Такая постановка проблемы требует учета психологического фактора в построении динамических моделей взаимодействия языковых процессов и социальных практик. В данной статье мы обратимся к потенциалу динамических моделей «языка в человеке», которые относятся к разряду сетевых и, как нам представляется, способны помочь в оценке выявившихся на постсоветском пространстве этносоциополитических аспектов функционирования языка. Сетевые динамические модели пригодны и для поиска ответов на фундаментальные вопросы лингвистики об актуальной вариативности языка, о социокоммуникативных условиях, запускающих языковые изменения. Вместе с тем эти 
модели позволяют учесть психологические аспекты социокоммуникативной деятельности человека.

\section{Динамика в синхронии и диахронии: языковая вариативность и языковые изменения}

Динамическое взаимодействие социальных и языковых процессов имеет пространственно-временную отнесенность, которая должна быть учтена в соответствующих моделях. Традиционным для лингвистики является разделение синхронных и диахронических подходов в рассмотрении языковых изменений, вызванных социальными факторами. Синхронный аспект преимущественно высвечивает проблему языковой вариативности. Для ее изучения лингвист идентифицирует и описывает социолингвистические переменные с их функциональной спецификой по уровням языка и характерной социальной дистрибуцией. Вариативность как естественное состояние языка может поставлять субстантный материал для языковых изменений, однако сама по себе не может быть к ним приравнена. Для оценки устойчивости и направленности изменений (в особенности на фонетическом и грамматическом уровнях) необходимо время, превышающее жизнь одного поколения наблюдателей.

Диахроническая социолингвистика ограничена в выборе методов и приемов исследования из-за невозможности живого, актуального наблюдения за предметно-содержательной стороной ушедшей в прошлое социальной и языковой деятельности. Ей приходится во многом опираться на готовые лексикографические и текстовые ресурсы, возможность обработки которых, впрочем, существенно расширилась с появлением компьютерных технологий. При этом обнаружение социально детерминированных языковых изменений макроуровневого порядка (затрагивающих эпохи и значительные пласты вербальных единиц), равно как и микроуровневая динамика значений отдельных лексем, базируется преимущественно на историческом анализе лексикографических источников и семантических категорий (часто представленных в виде полевых структур). Исследования такого плана необходимы для оценки и описания динамики ядра лексического состава языка и связанных с этой процедурой прикладных решений.

Диахроническая социолингвистика фиксирует ряд знаковых для второй половины прошлого века процессов в системе английского языка, интенсивно развивающихся и в новом тысячелетии. Так, Дж. Хьюз [Hughes, 1989], активно использующий приемы построения семантических полей лексики, объединенной социально-культурными условиями бытования, прибегает к данным Оксфордского словаря, в котором приводятся даты первого и последнего употребления слов в текстах. Семантические поля становятся предметом рассмотрения в исторической ретроспективе с учетом реконструкции по сохранившимся из прошлого источникам широкого социокультурного контекста, в котором функционировали рассматриваемые группы лексем в разные периоды их существования в языке. Социальный контекст восстанавливается параллельно с тематическими лексико-семантическими полями. При данном подходе автор получает материал, позволяющий не только выносить суждения о содержании наблюдаемых собственно языковых изменений, но и о детерминирующих реструктурирование лексикосемантических полей социальных факторах. Дж. Хьюзу удалось выявить такие социально обусловленные сдвиги в смысловой структуре больших групп лексики, как секуляризация религиозных терминов (clerk, cell, worship, passion утратили исходную исключительно сакральную отнесенность к религиозным практикам); морализация и демократизация статусных слов (например, noble, villain перешли из простых именований социального статуса в единицы оценочного типа, а значение слова free утратило исходные ассоциации с качествами, присущими только людям определенных сословий) и др. Рост экономики капитализма и зависимости от денежного оборота активирует специализацию значений по типу монетаризации, по данным Дж. Хьюза, с 1550 г. особенно экстенсивно и интенсивно, с вовлечением все большего количества слов, и с увеличением частоты их употребления [Hughes, 1989, p. 36-37]. Целый ряд лексем, называвших прежде более разнообразную по своему содержанию деятель- 
ность, ассоциируются теперь только с товарно-денежным обменом (ср. др.-англ. sellan'давать, отдавать, в том числе и в обмен на что-то'; совр. sell - 'продавать'). Влияние денег не только трансформировало семантику многих унаследованных от древнеанглийского языка слов, но и привело к появлению большого количества заимствований, которые отражают новые сферы деятельности и отношений в обществе: отношения собственности, налогообложение, кредитно-банковская сфера, коррупция и др. [Hughes, 1989, p. 3637]. Очевидно, что для рядовых носителей языка такого рода изменения не были заметны и осознаваемы, время их протекания превышало сроки жизни отдельных индивидов.

Ключевые механизмы языковых изменений при взаимодействии различных факторов подробно и новаторски раскрыты У. Лабовом на современном материале американского английского (ANAE) ${ }^{1}$. Автор последовательно идентифицирует субстантные, структурные и функциональные признаки, попадающие в разряд изменений, анализирует весь открывшийся на новом материале комплекс факторов, среди которых особое внимание уделяется когнитивным и культурным. Они осмысляются (на основе возрастной специфики восприятия и освоения языковых явлений) у детей как характерная для них трансмиссия (transmission of change), а у взрослых - диффузия (diffusion of change). Рассматривается большой спектр конвергентных и дивергентных явлений изменчивости, включая и такие, которые сопряжены, в той или иной степени, с разными актами идентификации носителей языка [Labov, 1994; 2001; 2007; 2010]. В итоге в лингвистике формируется системное представление о когнитивных и мотивационно-прагматических основаниях языковых изменений.

Работы У. Лабова и другие инициированные и проведенные выдающимися учеными исследования на английском материале [Chambers, Trudgill, 2004; Trudgill, 2014; Wolfram, Schilling-Estes, 2006] показали всю сложность и многофакторность языковой изменчивости. Ее характер, скорость, причинно-следственные механизмы существенно (иногда радикально) отличаются по уровням языковой системы. С точки зрения внутриязыковых закономерностей это обусловлено функциональной спецификой единиц каждого уровня и их подсистем, в частности, степенью влияния на понимание речи и передачу информации в процессе общения.

Информативна для понимания характера и природы воплощения социальных значений в единицах разного уровня статья П. Экерт и У. Лабова [Eckert, Labov, 2017], выполненная на фонетико-фонологическом материале. Авторы отмечают, что значения как конвенциональные ассоциации различий реального мира с различными языковыми формами по своей природе всегда социальны. В социолингвистическом плане актуальна социальность индексального порядка, то есть тот функциональный компонент значения, который несет информацию о говорящем как социальном акторе в речевой ситуации. Социолингвистическое значение в этом смысле возникает во взаимодействии между собеседниками. Заданный таким образом ракурс рассмотрения обязывает к исследованию связи референциальной составляющей с индексальной у единиц, показывающих вариативность на разных уровнях языковой системы. Конкретные фонетические единицы (звуки), свободные от смысловой референциальной нагрузки, склонны выполнять индексальную социальную функцию, в то время как парадигматические структуры абстрактно-фонологического уровня, неосознаваемые в своей совокупности носителем языка, служат в качестве маркеров социальных значений. Социолингвистическиепеременные, как правило, не выполняют референциальной функции, однако морфо-синтаксическая и лексико-прагматическая семантика языкового знака может усиливать его индексирующий социальность потенциал. Так, отрицание само по себе реализует референциальную функцию, в то время как количество негативных частиц выступает в качестве интенсификатора. Вариативность нагружает референциальный знак дополнительным индексирующим значением [Eckert, Labov, 2017, p. 469]. Само наличие макросоциальных параметров возраста, гендера, этничности не гарантирует обязательной индексации этих различий в языковом формате, но вероятность проявления этих параметров на локальном уровне рассмотрения конкретной разновидности языка у отдельного языкового коллекти- 
ва имеется. Следовательно, не любая вариативность в языке может быть социально значимой, однако переменные социолингвистического порядка направлены на высвечивание какого-то социально маркированного свойства. Они неустойчивы и изменчивы в той же мере, как и соответствующие социальные признаки [Eckert, Labov, 2017, p. 469].

Вопрос о языковых изменениях и их распространении авторы осмысляют с опорой на сетевую модель, в которой языковые изменения протекают по сети контактов между индивидами. Кластеризацию индивидуальных контактов исследователи ставят в зависимость от предметно-содержательной стороны совместной деятельности вступающих в контакт индивидов. Рассмотрев ряд сетевых параметров, усиливающих или ослабляющих социальную индексацию переменных, авторы приходят к выводу о том, что фундаментальное свойство языка человека - наличие в его арсенале ограниченного количества «пустых» в смысловом плане единиц, свободных от референции, но создающих при комбинировании друг с другом бесконечное количество несущих значение слов и предложений, - способствует передаче и распространению социально маркированных смыслов [Eckert, Labov, 2017, p. 491]. Движение значений лексических единии в их соииокоммуникативной обусловленности приобретает в этом плане, как нам думается, особую актуальность.

\section{Языковая вариативность и практика нормирования}

Влияние современных технологий СМИ на движение значений и связанные с ним механизмы языковых изменений по-разному оцениваются обывателями и социолингвистикой. На оси исторического времени вплоть до современного состояния языковых процессов жизнь технологий передачи на расстояние письменных, а тем более звуковых форм чрезвычайно мала по своей протяженности. По подсчетам П. Традгила, письменной традиции отведено не более $5 \%$ истории существования языка, а электронным средствам и того меньше - примерно 0,1 \% [Trudgill, 2014, p. 221]. Автор отмечает, что изменения были присущи языку во все периоды его существо- вания, задолго до технологических революций, давших человеку письменность и электронные средства передачи информации. Основные закономерности, которые приводят к изменениям, сокрыты преимущественно в прямом коммуникативном контакте (face-to-face communication), живой речевой деятельности людей и не возводятся к распространенному дилетантскому суждению о приоритетной роли СМИ. Она не может всерьез рассматриваться в случае с фонетическими и грамматическими изменениями, в отличие от лексических [Trudgill, 2014, p. 218].

Более того, Дж. Хьюз, рассуждая о вариативности современного английского языка в постколониальном контексте, обращает особое внимание на источники, формирующие лексическое ядро в разных стандартных вариантах этого языка. Он усматривает гораздо больше сходств между языком господствующих в мире журналистских практик СМИ, чем между речью индивидов в реальных сообществах носителей английского языка в разных странах (например, в Британии и Америке) [Hughes, 1989, p. 359]. Вместе с тем автор отмечает некоторые существенные изменения в ядре лексического состава современного английского, общие для разных вариантов этого языка, связывая их не только с технологическими инновациями последних десятилетий, но и с социокультурными последствиями глобализации при нарастающей американизации социальных практик. Одним из ярко выраженных признаков современного английского языка Дж. Хьюз считает рост подвижности границ между разными регистрами речи, что проявляет себя в конкретных группах лексем. Например, устаревание некогда центральных в ценностном плане лексем (sin, honour, soul, virginity); переход в сферу общеупотребительных слов экзотических (paparazzi, mafia, ghetto, assassin), специальных (stress, mess, guy, stuff), «классических литературных» (animal, basic, conversation, environment) лексем [Hughes, 2000, p. 369]. Если для создателей лексикографической традиции Оксфордского словаря на рубеже XIX и XX вв. главным ориентиром при отборе лексики и описании ядра лексического состава языка были лучшие образцы классической английской литературы, то специфика совре- 
менной эпохи, по утверждению Дж. Хьюза, заключается в том, что установить границы понятию литературного языка очень трудно, поскольку он впитал в себя огромные пласты обыденной просторечной и обсценной лексики, а образ литературного труда в настоящее время формируется на основе разнообразия новых критериев [Hughes, 2000, p. 335-336]. Эти особенности заставляют исследователя говорить о поиске новых подходов к описанию лексического ядра языка: он предлагает рассматривать данное понятие с опорой на критерий формальности, способной воплощаться в разных вариантах по шкале «болееменее» (formal, common, colloquial, slang, obscenity) и заменяющей прежнюю более жесткую категорию литературности [Hughes, 2000, p. 372-373].

Представляя специфику лексического состава английского языка в модели поля, группирующей разные лексическое слои вокруг общеупотребительного (common) ядра, Дж. Хьюз отмечает не только общую тенденцию к его неустойчивости, подвижности регистров речи, но и другие признаки, отражающие последствия американского «культурного империализма», брутализации (роста обсценной составляющей), пересмотра рубрик культурных табу, характерных в большей мере для языка молодежи [Hughes, 2000, p. 396397]). Изменение чувствительности к содержанию социально табуизированных сфер лингвист связывает со сменой ценностных императивов. Из двух полюсов сферы табу - неподлежащего упоминанию всуе сакрального (прежде преимущественно ассоциировавшегося с вопросами веры и религии) и невыразимо порочного - центр тяжести в плане употребительности и эмоциональной силы явно сместился в сторону второго. Появившаяся новая сфера табу маркирует расовые, этнические признаки выходцев из Африки и Азии, в меньшей степени из Ирландии, Шотландии, Уэлльса (nigger, paki, paddy, jock) и др. [Hughes, 2000, p. 396-397] ${ }^{2}$.

Подводя итоги краткому экскурсу в проблематику выявления ядра лексического состава, следует заметить, что в условиях постколониальной дивергенции английского языка, развития его вариативности на социокультурной основе, вопрос этносоциокуль- турной идентификации и использования языка в качестве ее инструмента выходит на первый план. Работа по поиску критериев научного описания языка в новообретенных форматах его вариативности не может не учитывать потребности в самоидентификации проживающих в разных странах и разной этносоциополитической реальности англоязычных народов. Во многих ключевых аспектах эта проблематика, которую можно также отнести к этнополитической социолингвистике, актуальна и для других мировых языков (включая русский) с характерной для них спецификой.

С развитием компьютерных технологий в лексикографии старые методы выявления ядра лексического состава с опорой на логический, историко-этимологический и историко-культурологический анализ лексического состава в его привязке к быстро уходящим в прошлое социальным практикам не смогут претендовать на самодостаточность. Стремление сохранить и сделать достоянием будущего богатство унаследованного от прошлого языкового наследия будет приходить в противоречие с психически актуальным использованием языка при отсутствии должного внимания к последнему со стороны профессионального сообщества, ответственного за фиксацию и нормирование языка.

\section{Индивид и сообщество: сетевые модели в социолингвистике и культурная идентичность}

При анализе языковой вариативности и социально обусловленных языковых изменений перед исследователем встает вопрос о содержании оппозиции «Индивид - Сообщество». Противоречия, которые она порождает, разрешаются, в частности, с помощью моделирования сети социальных контактов индивида, то есть выявления его отношений с другими индивидами: кто с ним общается, как часто, в каких именно условиях и контекстах, по каким поводам. Интенсивность и разветвленность индивидуальных контактов создают разноуровневую коммуникативную сеть социальных связей разной силы и плотности. Сам индивид рассматривается как субъект сетевых взаимодействий, представляющих собой 
кластеры родственных, дружеских, профессиональных и иных типов связей. Л. Милрой вводит понятие шкалы оценки сетевых характеристик говорящих (a Network Strength Scale), учитывающей обнаруженные в ходе полевых исследований параметры значимых контактов индивидов [Milroy, Gordon, 2003, p. 121]. В работах Дж. Милроя, Л. Милрой [Milroy, 1987; Milroy, Milroy, 1985] и других ученых выявляется зависимость между плотностью (силой или слабостью) коммуникативной сети, ее разветвленностью, тенденцией к внутренней интеграции и закрытости или наоборот, открытости для внешних контактов, и склонностью языка, который используется интегрированными в сеть индивидами, к изменчивости (или сохранности). Рассматривалось также влияние географической и социальной мобильности говорящих, сфер их экономической занятости, потребностей в идентификации и иных социально значимых аспектов жизнедеятельности на характер сети социальных контактов и соответствующие индексы интегрированности в нее говорящих. Было показано, что чем выше индекс плотности сети социальных контактов, тем глубже интегрирован говорящий в свое сообщество [Milroy, Gordon, 2003, p. 121]. Особо интересны для нас исследования процессов ослабления социокоммуникативной сети с вытекающими отсюда количественными и качественными последствиями для активизации языковых изменений [Milroy, Gordon, 2003, p. 127-130]. Эти параметры представляются нам актуальными для рассмотрения движения значений слов в постсоветском контексте.

Мы исходим из того, что формирование индивидуальной сети социальных контактов в значительной степени зависит от условий внешней среды. В онтогенезе социокоммуникативная сеть первична по отношению к субъекту как данность, подлежащая интериоризации наряду с другими предметно-содержательными культурными реалиями, включая тела языковых знаков и ассоциированные с ними значения, то есть язык как внешний объект. Ребенок испытывает воздействие социокоммуникативной сети длительное время, адаптируясь к ней и не будучи в состоянии произвольно управлять ею. В использовании и интерпретации полученных с помощью сетевых моделей данных, по нашим наблюдениям, можно наметить два подхода. Первый (удобен для изучения языковой интеграции малых социальных групп) - трактовка сети социальных контактов как индивидуального феномена, то есть достояния индивида. Назовем его условно «приоритет индивида». Он реализуется в работах большинства социолингвистов-англистов (см., например: [Hudson, 2007; 2010; Milroy, 1987; Milroy, Milroy, 1985]), которые критикуют традиционное понятие языкового сообщества (speech community) как относительно изолированного, имеющего преимущественно географическую локализацию образования. Такой подход представляется им неэффективным для объяснения динамики привнесенных глобализацией процессов социальной и языковой вариативности. Альтернативно предлагается трактовка места пребывания сообщества в качестве культурного концепта (для которого больше подходит английский термин «community of practice»), пригодного для изучения социолингвистических процессов в миграционном контексте [Milroy, Gordon, 2003, p. 134].

Второй подход декларирует приоритет сообщества, которое, как показывает на примере сдвига гласных Северных городов в США У. Лабов, концептуально (в культурноисторическом и когнитивном плане) первично по отношению к индивиду [Labov, 2010, p. 208235]. Сдвиг гласных Северных городов представляет собой важный маркер территориальной вариативности американского английского по границе континентального Севера и Центрального ареала. Эта граница, как свидетельствуют данные ANAE и специальные эксперименты на распознавание локализации информантов, уже более века является самой выраженной и устойчивой в диалектном континууме США [Labov, 2010, p. 235]. Последовательная реализация сдвига в городах Севера контрастирует с гетерогенностью вокалических систем городов Центрального ареала [Labov, 2010, p. 214]. Несмотря на то что сдвиг гласных Северных городов остается в поле неосознанного социального смысла, У. Лабов считает возможным трактовать его как эффект утвердившегося в течение нескольких поколений культурного империализма янки (Yankee Cultural Imperialism). Подробный ана- 
И.В. Шапошникова. Динамические модели в социолингвистике и социокоммуникативные установки

лиз культурной специфики ведения хозяйства и идеологической организации сообществ на новых землях в ходе продвижения на Запад старожильческого населения южан нагорья, сформировавших поселения центральных ареалов с одной стороны, и янки, продвигавшихся из разных регионов Новой Англии с другой, показал, что последние, в отличие от первых, продвигались целыми сообществами с высокой степенью сохранности взрослого населения на новой территории по истечении 10 лет. Янки строили города, располагая дома вдоль оживленных дорог, из-за особого внимания к грамотности школы и колледжи строились в приоритетном порядке. Южане же продвигались одиночными семьями и малыми группами, останавливаясь в изолированных сельских районах и не задерживаясь долго на новых местах [Labov, 2010, p. 213]. Организация жизни сообществ янки обеспечила продолжительный, постоянный контакт (преемственность) среди детского населения и сделала возможной целостную передачу фонологической системы на Севере. У. Лабов приходит к выводу о том, что речевое поведение индивида вряд ли может быть адекватно истолковано без знания сообщества, к которому он принадлежит. В рассматриваемом случае движущие механизмы звукового изменения на Севере передаются через культурную преемственность, предшествующую личному опыту индивида. Она не сводится только к непосредственному сетевому взаимодействию (face-to-face interaction). Член сообщества, осваивающий культурно значимые языковые формы, получает информацию о них в опыте, однако этот опыт далек от непосредственной актуальной коммуникации [Labov, 2010, p. 368-369]. Видимо, здесь У. Лабов имеет в виду то, что этот опыт не порождается в текущей коммуникативной ситуации, как другие социально маркированные смыслы, а является когнитивным и культурным наследием прошлого, закрепленным в разных видах деятельности. Автор также приводит показательные факты, подтверждающие, что такого рода информация усваивается детьми не старше 9-10 лет, поэтому в речи тех, кто оказался на Севере в более позднем возрасте, сдвига гласных не наблюдается [Labov, 2010, p. 8-9].

\section{Ассоциативно-вербальная сеть и динамика \\ социокоммуникативных установок русской языковой личности}

Нам представляется, что сетевые подходы должны учитывать следующий факт: малые социальные группы как исходные ячейки социокоммуникативной сети не находятся в вакууме, они включены в смысловое поле культуры, в котором действуют свои законы смыслообразования (смыслоутратности). Не только отдельные представители народов постсоветского мира, но и сами эти народы остаются частями большой социокоммуникативной среды в общегосударственном воплощении на суперэтническом (цивилизационном, общероссийском) уровне. Влияние общего для российской цивилизации смыслового поля культуры имеет разную интенсивность (силу, плотность) и экстенсивность (разветвленность, охват) в разных его частях (локусах) с прототипическими и менее явными, периферийными признаками. В СССР длительное время наблюдалась высокая устойчивость социокоммуникативных сетей с внутренней направленностью векторов интересов коммуникантов. Конец 80-х и 90-е гг. прошлого века отмечены значительными и глубокими изменениями социокоммуникативного плана.

В постсоветский период динамика социокоммуникативных сетей определялась во3действием целого комплекса факторов. Среди них: ликвидация партийно-хозяйственного и идеологического организующих начал, приведшая к радикальной смене характера экономической деятельности при распаде прежних производственных связей; обвальная деиндустриализация; повышенные ожидания от новых рыночных регуляторов и непонимание реальных механизмов работы капиталистического рынка. Отсутствие у большинства советских людей опыта общения с внешним миром на фоне открытия границ привело к оживлению внутренних и внешних миграционных процессов, смещению вектора интересов больших групп населения с внутреннего на внешний. Все это создало экстремальную ситуацию для большей части населения бывшего СССР. Характерный для смутного времени кризис подлинности (идентичности) проявил себя в кон- 
фликтности обессмысливающих друг друга смысловых образований в сознании людей. Это состояние личности психологи называют смыслоутратностью [Магомед-Эминов, 1998, c. 37]. Мы предполагаем, что противоречия смыслоутратности как социокультурного феномена независимо от их осознаваемости могут отразиться на социокоммуникативных установках языковой личности в тот период времени, когда они были для нее актуальны. Именно эти противоречия определяют в значительной мере и те деформации в языковой политике, которые были допущены в эпоху перестройки. Их исследование предполагает включение психологического фактора в рассмотрение социолингвистических реалий, поэтому может производиться в настоящее время с опорой на сетевую ассоциативно-вербальную модель «языка в человеке». С развитием ассоциативной лексикографии в последние десятилетия российская психолингвистика получила в свое распоряжение источники (ЕВРАС, РАС, САНРЯ, СИБАС) ${ }^{3}$, позволяющие оценивать динамику смысловых систем у нового поколения носителей русского языка. Преимущества такой модели, как ассоциативно-вербальная сеть (АВС) заключаются в ее актуальности и активности, доступности для статистической обработки и анализа всего массива ассоциатов (макроуровень) и отдельных ассоциативных полей (АП) (микроуровень). На макроуровне возможно не только выявить необходимое для системного анализа психически актуальное лексическое ядро (ассоциативные доминанты языковой личности), но и построить прилегающие к нему в разной степени удаленности и укорененности связей лексические слои, что очень важно для оценки вариативности языка и выработки стратегии его нормирования. Постоянное пополнение и обновление экспериментальной базы вербальных ассоциатов уже в настоящее время создает условия для исследований актуальной диахронии (с возможностью отслеживать динамику сети в пределах трех-четырех поколений).

Массовый ассоциативный эксперимент, проведенный в азиатских регионах России, выявил «ассоциативных лидеров» (на начало 2014 г.) по количеству реакций: человек (10 011), деньги (4 036), дом (2 584), друг (2 342). По количеству стимулов (укорененности смыслов в разнообразии связей) это: человек (450), жизнь (345), дом (335), деньги (263), хорошо (261), плохо (260), друг (253), нет (235), мир (232), я (230) (СИБАС). Сходную, хотя и не совсем идентичную, системную иерархию находим и в европейской части России: человек (594), жизнь (497), дом (465), плохо (269), хорошо (264), нет (257), деньги (249), мир (240), друг (236), я (215). (Данные ЕВРАС взяты из [Уфимцева, 2017, с. 95].) Сопоставление с рейтингом ассоциатов прошлого века показывает существенное продвижение ассоциата деньги (с 19-й позиции в САНРЯ на 8-ю в РАС, с сохранением лидерства в первой десятке в XXI в.) и я (не вошедшего даже в список первых тридцати лидеров САНРЯ, но начавшего постепенное восхождение в период перестройки и стремительно переместившегося в первую десятку лидеров ядра в XXI в.). Это отражает прошедшую смену предметно-содержательного опыта новых видов деятельности после перестройки и соответствующие сдвиги в социокультурных установках русской языковой личности. «Монетаризацию», как и другие отмеченные Дж. Хьюзом устойчивые изменения, можно отследить на микроуровне на материале отдельных сегментов АВС при сравнении данных нескольких десятилетий. Проведенные нами на этапе редактирования материалов СИБАС исследования показали, что в культуре пользования языком произошли серьезные трансформации. Заметна «брутализация» языкового сознания молодых россиян, что отражается не только в новоявленной прагматичности смыслов, небывалом наплыве прежде табуизированных форм вербальной оценки, но и в вытеснении реалий своего культурного поля на периферию смысловой структуры сознания. Пустота заполняется вульгарными инородными реалиями. «Брутализация» и «этнизация» языкового сознания отмечаются и на макро-, и на микроуровнях $\mathrm{ABC}$ носителей русского языка.

Психически актуальные социально обусловленные процессы могут быть выявлены и описаны в терминах психоглосс ${ }^{4}$, позволяющих увидеть трансформацию социально и культурно обусловленных лексических значений в поле личностных смыслов испытуемых. Здесь 
мы исходим из принятой в российской психолингвистике модели сознания как динамического процесса, в котором выявляются чувственная ткань образа, обеспечивающая субъекту связь с внешним миром, значения и личностный смысл. Чувственная ткань и личностный смысл психофизиологичны, индивидуальны; значения же надиндивидуальны, как социально-культурный продукт, результат коллективного опыта взаимодействия с ушедшим предметно-содержательным миром, они не психофизиологичны. Личностный смысл - это результат присвоения значений субъектом. Поэтому «движение значений» есть процесс смыслообразования, воплощение значений через чувственную ткань и личностный смысл у ныне живущих субъектов (более подробно о структуре сознания см.: [Леонтьев, 2005, с. 91-96]). Онтогенетически, «вживляясь» в окружающую среду в ходе активной деятельности, человек интериоризирует («вращивает» внутрь) через чувственную ткань и личностные смыслы весь свой вербальный и социокоммуникативный опыт взаимодействия с миром. $\mathrm{ABC}$ как часть когнитивной сети человека содержит проекцию социокоммуникативной сети испытуемых, что дает нам шанс на изучение следов ее функционирования, которые сигнализируют о социокоммуникативных установках языковой личности применительно к актуальному использованию языковых знаков. АВС должна отразить в той или иной мере ослабление (или наоборот, усиление) связей внешней социокоммуникативной сети. Это можно проверить на макро- и микроуровнях анализа. Выявить изменчивость, измерить и интерпретировать ее можно, в частности, с помощью когнитивных и мотивационно-прагматических психоглосс, показывающих векторы смыслообразования или смыслоутратности у языковой личности.

В отличие от моделей индивидуальных кластеров внешних сетей социальных контактов $\mathrm{ABC}$ представляет собой комплексный, многомерный объект, способный отразить все факторы (включая осознаваемые и частично неосознаваемые), попадающие под рубрику социальных (social dimensions). Экспериментально доказанная возможность получить через $\mathrm{ABC}$ доступ к усредненной языковой личности и фундаментальные положения о ее природе, выработанные в отечественной на- уке на русском материале [Караулов, 2010], мотивируют ученых использовать ассоциативно-вербальные методики для исследования процессов социокультурной идентификации. $\mathrm{ABC}$ пригодны для анализа социально и культурно значимых явлений, которые могут представлять интерес не только сами по себе, но и в качестве условий для возникновения языковой вариативности и языковых изменений.

Под социокоммуникативными установками мы понимаем установки на использование тех или иных вербальных единиц в определенных отношениях и связях, выработавшихся в ходе сложившихся в рассматриваемый период социокоммуникативных практик. Интенсивность (сила) связей ассоциатов в сети находит отражение в частотных показателях: единожды встретившиеся ассоциаты условно выделяются как периферия АП, а все повторяющиеся с разной частотностью - как ядро, что не исключает разную степень интенсивности его компонентов. Экстенсивность (укорененность в разнообразии связей) измеряется количеством разных реакций в структуре АП.

Рассмотрим некоторые признаки динамики смысловых процессов на примере АП «народ» (см. табл. 1) в связи с отмеченным нами ослаблением сети социальных контактов во внутреннем пространстве бывшего CCCP.

В АП «народ» отчетливо выявляется 6 смысловых зон. Статистика их интенсивности в САНРЯ, РАС, СИБАС и ЕВРАС (в процентах от общего количества реакций в устойчивой части и на периферии) приводится в таблице 2.

Психоглоссы, которые выявляются при анализе конкретных ассоциатов в каждой смысловой зоне, отчетливо показывают движение доминантных смыслов во времени. Это движение поддается интерпретации в контексте оппозиций: народ (люди) vs. толnа; онтологическое единство vs. случайное сборище, безликая масса; народ vs. скот; активность, иелеполагание vs. пассивность, стихийная спонтанность; планетарность vs. местечковость; глобально общегосударственный, ииивилизационный vs. локально этнический, национально-расовый контекст; трудовая деятельность vs. развле- 
Сравнительный анализ АП «народ» в САНРЯ, РАС, СИБАС и ЕВРАС

\begin{tabular}{|l|c|c|c|c|}
\hline $\begin{array}{c}\text { Общая структура } \\
\text { и наполнение } \\
\text { ассоциативных полей }\end{array}$ & $\begin{array}{c}\text { САНРЯ } \\
(1970-\text { гг. })\end{array}$ & $\begin{array}{c}\text { РАС } \\
(1988-1997)\end{array}$ & $\begin{array}{c}\text { СИБАС } \\
(2008-2013)\end{array}$ & $\begin{array}{c}\text { ЕВРАС } \\
(2008-2013)\end{array}$ \\
\hline Разные & 75 & 67 & 205 & 185 \\
\hline Единичные & 54 & 52 & 154 & 124 \\
\hline Устойчивые & 148 & 57 & 342 & 401 \\
\hline Отказы & 0 & 0 & 6 & 8 \\
\hline \multicolumn{1}{|c|}{ Всего реакций } & $\mathbf{2 0 2}$ & $\mathbf{1 0 9}$ & $\mathbf{5 0 2}$ & $\mathbf{5 3 3}$ \\
\hline
\end{tabular}

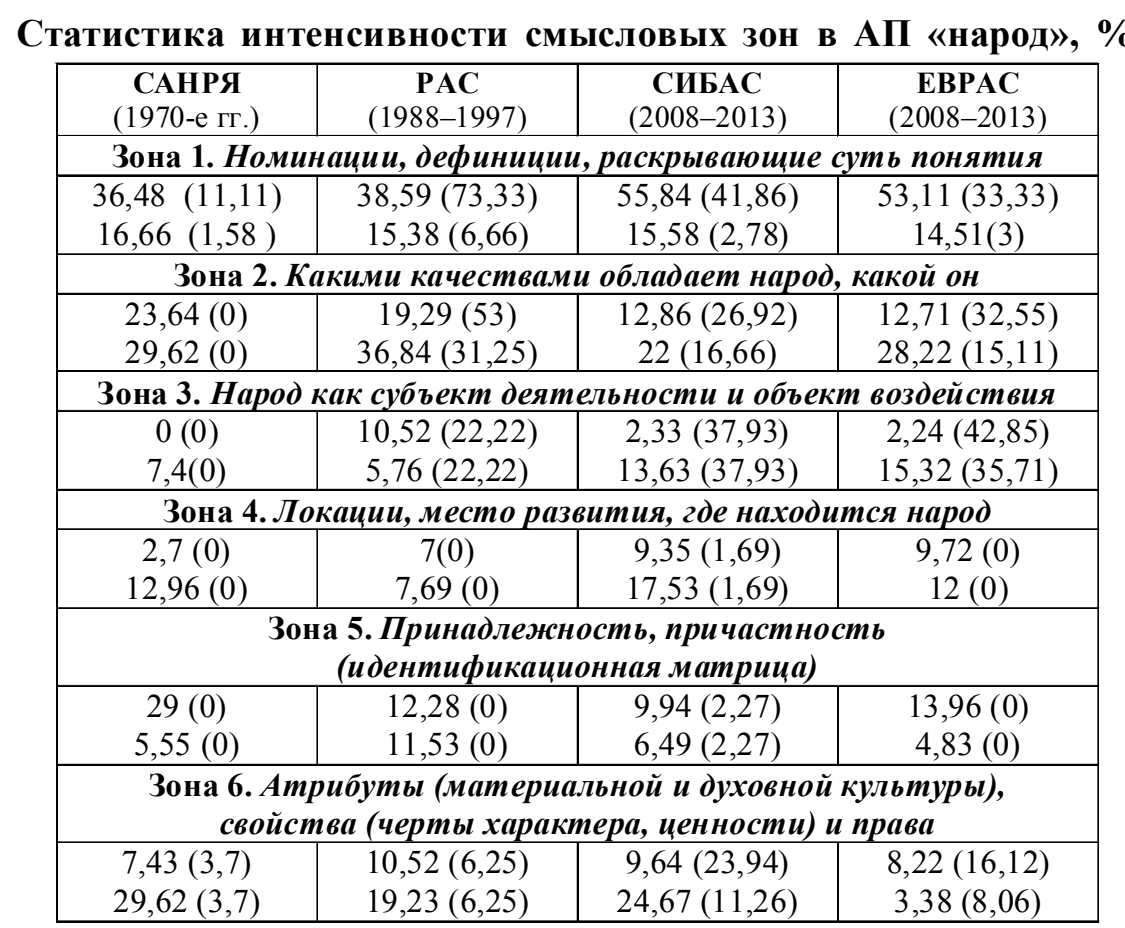

Таблица 2

Примечание. Данные по ядру каждой зоны приводятся первыми, периферии - вторыми. В скобках указывается \% негативно-оценочных ассоциатов от общего количества реакций в каждой зоне.

чения и гедонизация; позитивно vs. негативно оценочные смысльы. В разные периоды времени в каждой из смысловых зон центр тяжести смещался в ту или иную сторону в пределах каждой из этих оппозиций, а специфическое сочетание совокупно явленных при этом смысловых воплощений (граней) образа «народ» соответствовало специфике эпохи. Так, в 70-е гг. прошлого века (САНРЯ) образ народа устойчиво позитивен, непротиворечив: народ выступает как творческая (движущая) сила, имеющая статус нации и способная к целеполаганию, как творец, победитель и труженник. В перестройку (РАС), напротив, центр тяжести первой зоны переместился в сторону тотального негатива. Ср.: САНРЯ: люди 39; толпа 6; масса 5; нация, твореи 2; РАС: толпа 16; быдло, массы, стадо $2^{5}$. Признаки смыслоутратности характерны и для зоны 2: исключительно позитивный и самодостаточный образ 70-х гг. уступил место негативно-оценочному перестроечному, с акцентами озлобления, глупости, голода и бедности, страдания и загнанности. В зоне 6 устойчиво самодостаточные сила, дружба и труд в ядре САНРЯ сменяются политизированными ассоциатами с партией, дополненными целым рядом единичных, создающих противоречивую картину жалостливости и бунта на фоне политических реалий перестройки (выборы, Ельцин и пр.).

В XXI в. (ЕВРАС, СИБАС) у детей смутного времени смыслоутратность не преодолена. Негативная оценочность охватывает 
практически все зоны. Отраженный в них автостереотип противоречив и неустойчив. Так, члены оппозиции народ (люди) vs. толnа почти равновесны, конкретное содержание других ассоциатов претерпело существенную трансформацию в сторону акцентуаций национального, местечкового родоплеменного и даже расового контекста. Сказывается отсутствие у молодых людей единого целеполагания, совместного опыта деяний цивилизационного формата. В РАС фиксируется значительная расшатанность социокультурной идентичности, в СИБАС и ЕВРАС отражается некоторая мобилизация сознания, восстановление утраченного в перестройку позитива, но образ все еще противоречив. Народ предстает скорее как ведомая враждебношумящая и объединяющаяся против власти толnа, чем организованная, способная к жизнестойкому целеполаганию сила. К озлоблению с 90-х гг. добавились негативные смыслы обманутости, нищеты, жестокости, враждебности и дикости (варварства). Проявляются смыслы, характерные для господства гедонистической модели как фактора толпообразования. Яркие противоречия между жизнью и смертью, весельем, гуляньем и ликованием с одной стороны, и озлоблением, голодным бунтом яростной и бушующей «обманутой» толпь с другой. Преобладающие в зоне 4 САНРЯ элементы планетарного мышления почти исчезают в РАС, значимость событий внутри страны (СССР) выходит на первый план. В СИБАС и ЕВРАС фиксируется частичное восстановление картины с абсолютным преобладанием контекста страны-России и местечковых смыслов. В зоне 5 САНРЯ суперэтническая идентификация (советский) - самая устойчивая. На фоне радикализации идентифицирующих переоценок 90-х гг. усиливается этнический контекст: русский подавляет советский. Российская идентичность (новообразование XXI в.) явно выражена в СИБАС, в то время как в ЕВРАС она присутствует в импликациях многонациональный и православный. Здесь ярче выражен именно русский (супер)этнический план. Зона 6 претерпела кардинальную содержательную перестройку. Из прежних устойчивых реакций советского времени воспроизводится только сила. Труд, дружба, армия, партия и даже культура с историей уже не актуальны для нового образа. В нем преобладают акценты на демократии, власти и силе, вхожи новые смыслы единения, государственности, выборов, верности, свободы и пр. Ядро устойчиво насыщается негативными смыслами толпообразования (бунт, восстание, глупость), которые усиливаются за счет периферии. Ощущение разобщенности, характерное для местечкового образа народа, порождает тенденцию к единению (сплочению) в новое время, для многих не подкрепленную иными видами деятельности кроме развлечений.

\section{Выводы}

Ассоциативно-вербальные сетевые модели, будучи гибкими динамическими системами, отражают структуру и содержание социокоммуникативных установок языковой личности с учетом изменчивости ее смысловых акцентов. Вербальные ассоциации несут информацию об этносоциокультурных сферах, в которых осуществляются коммуникативные акты и кристаллизуется мотивационная структура языковой личности. Такие трансформации в сети социальных контактов сообщества носителей русского языка, как смена ее ориентации (внутрь - вовне), сфер деятельности и социально-экономического уклада, ослабление связей и плотности контактов приводят к трансформации социокоммуникативных установок, что становится очевидным в пределах $\mathrm{ABC}$ трех поколений и маркируется статистикой психоглосс (направленности смысловых акцентуаций). Изменения социокоммуникативных установок могут стать социально и психически обусловленной базой для будущей трансформации значений слов. Изучение вариативности и языковых преобразований в пределах актуальной диахронии при условии накопления новых экспериментальных данных может способствовать развитию ассоциативной вариантологии и этнополитической социолингвистики. Экспериментально полученные сетевые модели «языка в человеке» должны использоваться при взаимной верификации данных, полученных иными социолингвистическими методами. 


\section{ПРИМЕЧАНИЯ}

${ }^{1} A N A E$ - Labov W., Ash Sh., Boberg Ch., 2006. The Atlas of North American English. Phonetics, Phonology and Sound Change. Berlin ; N.Y. : Mouton de Gruyter. 318 p.

${ }^{2}$ На особую чувствительность к социальным различиям с расовой и этнической подоплекой в США указывают и другие исследователи (см., например: [Milroy, Gordon, 2003, p. 108112]). Расовая и этническая принадлежность переплетается со спецификой иммиграции в разных частях США, классовой принадлежностью и деклассированием некогда благополучных этнических меньшинств в новых условиях мегаполисов, устойчиво сохраняющимися тенденциями к сегрегации в американской культуре. Все эти сложные проявления социальных противоречий имеют локальную специфику, поэтому сеть социальных контактов в каждом из таких сообществ имеет свои особенности, а языковые проявления этничности варьируются очень существенно от сообщества к сообществу [Milroy, Gordon, 2003, p. 108-112, 115].

${ }^{3}$ В 70-е гг. ХХ в. был создан словарь ассоциативных норм (САНРЯ), в период с 1988 по 1997 г. - ассоциативный тезаурус (РАС) на основе трехэтапного массового эксперимента с постепенным наращиванием АВС. Новейшие данные были получены в параллельном для азиатской и европейской частей России эксперименте, они сгенерированы в ассоциативные словари 2008-2013 гг. (ЕВРАС, СИБАС), полностью сопоставимые по репрезентативности и составу единиц. Экспериментальные региональные базы данных в настоящее время содержат материалы одного этапа массового эксперимента (каждая из них включает ассоциаты, полученные на 1000 стимулов от 500 условных испытуемых, что составляет не менее 5000 анкет, по 100 стимулов в каждой, предъявленных 5000 студентов в каждом регионе).

${ }^{4}$ Психоглоссы - маркеры смысловых акцентуаций, которые выявляются при статистической обработке АП. Статистика позволяет измерить направленность смысловых акцентуаций в его структуре. В термине «психоглосса» элемент «психо-» указывает на психическую природу смысловой акцентуации, которая представляет собой часть смысловой структуры образа мира языковой личности испытуемых, «-глосса» - на вербализованный характер смысла, его явленность носителю языка в виде языковых единиц [Шапошникова, 2018].

${ }^{5}$ Цифры показывают частоту актуализации ассоциата в эксперименте.

\section{СПИСОК ЛИТЕРАТУРЫ}

Губогло М. Н., 2016. Этносоциология и этнополитология в системе междисциплинарного знания // Феномен междисциплинарности в отечественной этнологии / отв. ред. и сост. Г. А. Комарова. М. : ИЭА РАН. С. 70-77.

Караулов Ю. Н., 2010. Русский язык и языковая личность. 7-е изд. М. : Изд-во ЛКИ. 264 с.

Леонтьев А. Н., 2005. Лекции по общей психологии. М. : Смысл : КДУ. 511 с.

Магомед-Эминов М. Ш., 1998. Трансформация личности. М. : ПАРФ. 494 с.

Тишков В. А., 2016. Новая политическая антропология // Феномен междисциплинарности в отечественной этнологии ; отв. ред. и сост. Г. А. Комарова. М. : ИЭА РАН. С. 100-105.

Уфимцева Н. В., 2017. Этнопсихолингвистика как раздел теории речевой деятельности // (Нео)психолингвистика и (психо)лингвокультурология: новые науки о человеке говорящем : коллектив. моногр. / И. А. Бубнова, И. В. Зыкова, В. В. Красных, Н. В. Уфимцева; подред. В. В. Красных. М. : Гнозис. С. 21-96.

Феномен междисциплинарности в отечественной этнологии, 2016 / отв. ред. и сост. Г. А. Комарова. М. : ИЭА РАН. 458 с.

Шапошникова И. В., 2018. Психоглоссы, маркирующие цивилизационную идентификацию российских студентов (по материалам массовых ассоциативных экспериментов) // Сибирский филологический журнал. № 3. С. 255273. DOI: $10.17223 / 18137083 / 64 / 23$.

Chambers J. K., Trudgill P., 2004. Dialectology. Cambridge : Cambridge University Press. 201 p.

Eckert P., Labov W., 2017. Phonetics, phonology and social meaning // Journal of Sociolinguistics. Vol. 21, iss. 4. P. 467-496.

Hudson R. A., 2007. Language Networks. The New Word Grammar. Oxford: Oxford University Press. $275 \mathrm{p}$.

Hudson R. A., 2010. An Introduction to Word Grammar. Cambridge Textbooks in Linguistics. Cambridge : Cambridge University Press. 332 p.

Hughes G., 1989. Words in Time. A Social History of the English Vocabulary. Oxford: Basil Blackwell. $271 \mathrm{p}$.

Hughes G., 2000. A History of English Words. Oxford : Blackwell Publishers. 428 p.

Labov W., 1994. Principles of Linguistic Change. Vol. 1. Internal Factors. Oxford: Basil Blackwell. 664 p.

Labov W., 2001. Principles of Linguistic Change. Vol. 2. Social Factors. Oxford : Blackwell Publishers. $592 \mathrm{p}$.

Labov W., 2007. Transmission and diffusion // Language. № 83. P. 344-387. 
И.В. Шапошникова. Динамические модели в социолингвистике и социокоммуникативные установки

Labov W., 2010. Principles of Linguistic Change. Vol. 3. Cognitive and Cultural Factors. Oxford : WileyBlackwell. 448 p.

Milroy J., Milroy L., 1985. Linguistic change, social network and speaker innovation // Journal of Linguistics. Vol. 21, iss. 2. P. 339-384.

Milroy L., 1987. Language and Social Networks. $2^{\text {nd }} e d$. Oxford: Blackwell. 232 p.

Milroy L., Gordon M., 2003. Sociolinguistics: method and interpretation. Malden : Blackwell Publishing Ltd. $261 \mathrm{p}$.

Trudgill P., 2014. Diffusion, drift, and the irrelevance of media influence// Journal of Sociolinguistics. Vol. 18, iss. 2. P. 214-222.

Wolfram W., Schilling-Estes N., 2006. American English. Dialects and Variation. $2^{\text {nd }}$ ed. Malden : Blackwell Publishing Ltd. 452 p.

\section{ИСТОчнИкИ}

$E B P A C$ - Русский региональный ассоциативный словарь-тезаурус ЕВРАС / сост. Н. В. Уфимцева, Г. А. Черкасова. 2014. URL: http://ilingran.ru/main/publications/evras (дата обращения: 03.03.2019).

$P A C$ - Русский ассоциативный словарь / сост. Ю. Н. Караулов, Ю. А. Сорокин, Е. Ф. Тарасов, Н. В. Уфимцева, Г. А. Черкасова. М., 1994-1998. T. 1-2. URL: http://www.tesaurus.ru/ dict/dict.php (дата обращения: 03.03.2019).

САНРЯ - Словарь ассоциативных норм русского языка / под ред. А. А. Леонтьева. М. : Изд-во Моск. ун-та, 1977. URL: http://it-claim.ru/ Projects/ASIS/Leont/Index.htm (дата обращения: 03.03.2019).

СИБАC-Русская региональная ассоциативная база данных. Сибирь и Дальний Восток-2008-2018 / авт.-сост.: И. В. Шапошникова, А. А. Романенко. URL: http://adictru.nsu.ru (дата обращения: 03.03.2019).

\section{REFERENCES}

Guboglo M.N., 2016. Etnosotsiologiya i etnopolitologiya $\mathrm{v}$ sisteme mezhdistsiplinarnogo znaniya [Ethnosociology and Ethnopolitology in the System of Interdisciplinary Knowledge]. Komarova G.A., ed. Fenomen mezhdistsiplinarnosti $v$ otechestvennoy etnologii [The Phenomenon of Interdisciplinarity in Russian Ethnology]. Moscow, IEARAN, pp. 70-77.

Karaulov Yu.N., 2010. Russkiy yazyk i yazykovaya lichnost [Russian Language and Linguistic Personality]. Moscow, Izd-vo LKI. 264 p.
Leontyev A.N., 2005. Lektsii po obshchey psikhologii [Lectures in General Psychology]. Moscow, Smysl Publ., KDU Publ. 511 p.

Magomed-Eminov M.Sh., 1998. Transformatsiya lichnosti [Transformation of Personality]. Moscow, PARF Publ. 494 p.

Tishkov V.A., 2016. Novaya politicheskaya antropologiya [New Political Anthropology]. Komarova G.A., ed. Fenomen mezhdistsiplinarnostiv otechestvennoy etnologii [The Phenomenon of Interdisciplinarity in Russian Ethnology]. Moscow, IEA RAN, pp.100-105.

Ufimtseva N.V., 2017. Etnopsikholingvistika kak razdel teorii rechevoy deyatelnosti [Ethnopsycholinguistics as a Branch of the Theory of Speech Activity]. Bubnova I.A., Zykova I.V., Krasnykh V.V., Ufimtseva N.V., eds. (Neo)psikholingvistika $i$ (psikho)lingvokulturologiya: novye nauki o cheloveke govoryashchem: kollektiv. monogr. [(Neo)psycholinguistics and (Psycho)linguoculturology: New Sciences About Номо Loquens. Collective Monograph]. Moscow, Gnozis Publ., pp. 21-96.

Komarova G.A., ed., 2016. Fenomen mezhdistsiplinarnosti $v$ otechestvennoy etnologii [The Phenomenon of Interdisciplinarity in Russian Ethnology]. Moscow, IEA RAN. 458 p.

Shaposhnikova I.V., 2018. Psikhoglossy, markiruyushchie tsivilizatsionnuyu identifikatsiyu rossiyskikh studentov (po materialam massovykh assotsiativnykh eksperimentov) [Psychoglosses of the Civilizational Identity of Russian Students (Based on Large-Scale Associative Experiments)]. Sibirskiy filologicheskiy zhurnal [Siberian Journal of Philology], no. 3, pp. 255-273. DOI: $10.17223 / 18137083 / 64 / 23$.

Chambers J.K., Trudgill P., 2004. Dialectology. Cambridge, Cambridge University Press. $201 \mathrm{p}$.

Eckert P., Labov W., 2017. Phonetics, Phonology and Social Meaning. Journal of Sociolinguistics, vol. 21, iss. 4, pp. 467-496.

Hudson R.A., 2007. Language Networks. The New Word Grammar. Oxford, Oxford University Press. $275 \mathrm{p}$.

Hudson R.A., 2010. An Introduction to Word Grammar. Cambridge Textbooks in Linguistics. Cambridge, Cambridge University Press. 332 p.

Hughes G., 1989.Words in Time. A Social History of the English Vocabulary. Oxford, Basil Blackwell. 271p.

Hughes G., 2000. A History of English Words. Oxford, Blackwell Publishers. $428 \mathrm{p}$.

Labov W., 1994. Principles of Linguistic Change. Vol. 1. Internal Factors. Oxford, Basil Blackwell. $664 \mathrm{p}$. 


\section{ГЛАВНАЯ ТЕМА НОМЕРА}

Labov W., 2001. Principles of Linguistic Change. Vol. 2. Social Factors. Oxford, Blackwell Publishers. 592 p.

Labov W., 2007. Transmission and Diffusion. Language, no. 83, pp. 344-387.

Labov W., 2010. Principles of Linguistic Change. Vol. 3. Cognitive and Cultural Factors. Oxford, Wiley-Blackwell. $448 \mathrm{p}$.

Milroy J., Milroy L., 1985. Linguistic Change, Social Network and Seaker Innovation. Journal of Linguistics, vol. 21, iss. 2, pp. 339-384.

Milroy, L., 1987. Language and Social Networks. $2^{\text {nd }}$ ed. Oxford, Blackwell. $232 \mathrm{p}$.

Milroy L., Gordon M., 2003. Sociolinguistics: Method and Interpretation. Malden, Blackwell Publishing Ltd. $261 \mathrm{p}$.

Trudgill P., 2014. Diffusion, Drift, and the Irrelevance of Media Influence. Journal of Sociolinguistics, vol. 18 , iss. 2, pp. 214-222.

Wolfram W., Schilling-Estes N., 2006. American English. Dialects and Variation. 2nd ed. Malden, Blackwell Publishing Ltd. 452 p.

\section{SOURCES}

Ufimtseva N.V., Cherkasova G.A., eds. Russkiy regionalnyy assotsiativnyy slovar-tezaurus EVRAS [Russian Associative DictionaryThesaurus EVRAS]. 2014. URL: http://iling-ran.ru/ main/publications/evras (accessed 3 March 2019).

KaraulovYu.N., Sorokin Yu.A., TarasovE.F., Ufimtseva N.V., Cherkasova G.A. Russkiy assotsiativnyy slovar [Russian Associative Dictionary]. Moscow, 1994-1998, vol. 1-2. URL: http://www. tesaurus.ru/ dict/dict.php (accessed 3 March 2019).

Leontyev A.A., ed. Slovar assotsiativnykh norm russkogo yazyka [Dictionary of Associative Norms of the Russian Language]. Moscow, Izd-vo Moskovskogo universiteta, 1977. URL: http://it-claim.ru/Projects/ ASIS/Leont/Index.htm (accessed 3 March 2019).

Shaposhnikova I.V., Romanenko A.A., eds. Russkaya regionalnaya assotsiativnaya baza dannykh. Sibir i Dalniy Vostok - 2008-2018 [Russian Regional Associative Database. Siberia and Far East-2008-2018]. URL: http://adictru.nsu.ru (accessed 3 March 2019).

\section{Information about the Author}

Irina V. Shaposhnikova, Doctor of Sciences (Philology), Professor, Chief Researcher, Institute of Philology of Siberian Branch of RussianAcademy of Sciences, Nikolaeva St., 8, 630090 Novosibirsk, Russia; Professor, Department of Intercultural Communication, Department of General and Russian Linguistics, Novosibirsk State University, Pirogova St., 2, 630090 Novosibirsk, Russia, i.shaposhnickowa@yandex.ru, https://orcid.org/0000-0003-3519-1209

\section{Информация об авторе}

Ирина Владимировна Шапошникова, доктор филологических наук, профессор, главный научный сотрудник, Институт филологии Сибирского отделения РАН, ул. Николаева, 8, 630090 г. Новосибирск, Россия; профессор кафедры межкультурной коммуникации, профессор кафедры общего и русского языкознания, Новосибирский государственный университет, ул. Пирогова, 2, 630090 г. Новосибирск, Россия, i.shaposhnickowa@yandex.ru, https://orcid.org/0000-0003-3519-1209 